\title{
Territorios de paz: otras territorialidades en la Comunidad de Paz de San José de Apartadó, Colombia ${ }^{1}$
}

\author{
Christopher Courtheyn²
}

Artículo traducido al español publicado en la revista Territorios y artículo en el idioma original publicado en The Journal of Peasant Studies

\footnotetext{
1 Agradecimientos especiales a Christopher Courtheyn, así como a la Revista Territorios por permitirnos publicar este artículo tan relevante para la temática de este número. Fuente en el idioma original: Christopher Courtheyn (2018) Territories of peace: alter-territorialities in Colombia's San José de Apartadó Peace Community, The Journal of Peasant Studies, 45:7, 1432-1459, DOI: 10.1080/03066150.2017.1312353. Fuente de la traducción: Courtheyn, Christopher. (2019). Territorios de paz: otras territorialidades en la Comunidad de Paz de San José de Apartadó, Colombia. Territorios, (40), 291-318. Recuperado de http://www.scielo.org.co/scielo.php?script=sci_arttext\&pid=S0123$84182019000100291 \& \operatorname{lng}=$ en\&tlng=es.

2 IProfesor Principal, Pro- grama de Gestión y Desarrollo Urbanos, Facultad de Ciencia Política, Gobierno y Relaciones Internacionales, Universidad del Rosario. Doctor en Geografía, Universidad de Carolina del Norte, Chapel Hill. Pregrado en Estudios Latinoamericanos, Universidad de California, Berkeley.
} 


\section{Resumen}

ELos académicos re-teorizan cada vez más sobre lo que es el territorio, trascendiendo el concepto de Estado-nación, debido a las exigencias de los grupos indígenas y afrodescendientes porque se les conceda un 'territorio', al verse confrontados con el acaparamiento de tierras en América Latina. Sinembargo, lasterritorialidades alternativas no se limitan a estos grupos étnicos. Partiendo de una investigación etnográfica de 16 meses, entre 2011 y 2016, exploro la territorialidad relacional generada por la Comunidad de Paz campesina en San José de Apartadó, Colombia. Partiendo del seguimiento al sujeto político colectivo producido por la activa generación de paz de la Comunidad de Paz mediante un conjunto de prácticas de espacios, lugares y valores, incluyendo conmemoraciones de masacres, iniciativas de soberanía alimentaria y redes de solidaridad entre indígenas y campesinos, este artículo presenta un marco conceptual para analizar diversas formaciones territoriales.

Palabras clave: Territorio, paz, acapara- miento de tierra, movimientos sociales, campesinos, Colombia. 


\section{Introducción: Repensar el territorio por medio de la coyuntura 'de paz' de Colombia}

Una literatura cada vez más vasta está reteorizando el concepto de territorio en relación con las crecientes demandas de 'territorio' y 'autonomía' por parte de campesinos indígenas y afrodescendientes que a lo largo de América Latina hacen resistencia al acaparamiento detierras (Escobar, 2008; Reyes \& Kaufman, 2011; Porto Gonçalves, 2006; Dávalos, 2011; Ulloa, 2012; Heasbaert, 2011). El 'territorio' se entiende habitualmente como un área limitada, controlada por una persona, por un grupo o en asociación con el Estado- nación soberano. Sin embargo, estos académicos sugieren que tales comunidades no replican ese tipo de soberanía a escala local, pero que sí reflejan estructuras culturales y políticas alternativas. De modo similar, los geógrafos han articulado concepciones más amplias de la "territorialidad" definiéndola como la relación que tienen los sujetos con el espacio-exterioridad (Raffestein, 2012; Reyes, 2015) en que se perciben las pretensiones de controlar el área como "propia" como una única forma. Para profundizar más aún esta concepción de los académicos, se necesita un marco analítico específico que sirva para diferenciar diversas formas de territorio. Al presentar las prácticas corporalizadas de una Comunidad de Paz de campesinos $^{3}$ en San José de Apartadó, Colombia, este artículo presenta un marco conceptual para analizar distintas formaciones territoriales, Ilamando la atención sobre los sujetos políticos generados por un conjunto territorial de prácticas, lugares y valores dado, en su relación con el espacio. A diferencia del 'Proceso de Paz' formal entre el Gobierno colombiano y la guerrilla de las Fuerzas Armadas Revolucionarias de Colombia (faRc), destaco cómo la comprensión y la creación de una paz vernácula de la Comunidad de Paz promulgan una forma y una conceptualización alternativas de territorio que yo llamo otra territorialidad o territorialidad alterna. 
La coyuntura de paz colombiana es particularmente fructífera para enriquecer los debates acerca del territorio porque, entre nociones contrastadas de paz, podemos discernir sobre los procesos conflictivos de procesos de territorialización. La idea de paz propuesta por el Gobierno colombiano está atada a una noción de territorio, ligada a nociones de seguridad nacional y desarrollo capitalista: El presidente colombiano Juan Manuel Santos anuncia el 'Proceso de Paz' como un medio para promover el modelo de desarrollo del país orientado a las exportaciones (El Espectador, 2014; Santos, 2015), congruente con las economías extractivistas extendidas a lo largo de América Latina (Bebbington, 2009; Gudynas, 2015).

Pero, si se considera lo que significa la paz para las comunidades campesinas, podemos ver surgir otra forma de territorialidad. En 1997, durante un periodo de intensa confrontación a nivel nacional entre paramilitares con el apoyo de fuerzas del Estado y la guerrilla a finales de la década de 1990, un grupo de campesinos de ascendencia principalmente indígena ${ }^{4}$,

3 Prefiero utilizar el término castellano 'campesino' (hago esta aclaración como angloparlante que escribe el presente trabajo en su lengua materna) en vez del generalmente correspondiente 'peasant' en inglés para evitar la carga peyorativa de este último - aunque equivocada- asociado con la interpretación menospreciante de Marx y Engels (1978) de los peasants como "no revolucionarios pero sí [...] reaccionarios, puesto que tratan de devolver la rueda de la historia" (p. 482). Estoy de acuerdo con Burnyeat (2013), quien afirma que "'campesino' [en castellano, como el texto de la cita, no en inglés] constituye toda una categoría cultural en Colombia y otras partes de Latinoamérica que no está expresado con precisión con" peasant o smallscale farmer (p. 3). Además, en conversaciones con Zamosc (1986), Fanon (2004) y Guha (1983), empleo 'campesino' para hacer alusión a los aspectos raciales, sociales y políticos de este sujeto específico.

4 Los agricultores de San José se identifican a sí mismos como 'campesinos', lo que en este caso tiene una correlación con la categoría étnica de mestizo. Sin embargo, las teorías que entienden la racialización como el "sujeto en esta posición" más que la mera "identidad" (Fanon, 2008; Goldberg, 2009; Wilderson, 2010), la historia de colonialismo interno conducido por medio de las misiones y la educación en manos conjuntas del Estado y la Iglesia católica en Antioquia (Steiner, 2000),así 
que luchaba por hacer resistencia a los asesinatos masivos y al desplazamiento forzado en la región de Urabá, se declaró a sí mismo una Comunidad de Paz en San José de Apartadó. La ubicación estratégica de Urabá para el tráfico de armas y drogas de y hacia Norteamérica, así como también su tierra fértil, sus plantaciones de banano, sus reservas de agua y minerales, codiciadas todas por los intereses del Estado, las empresas y los insurgentes, hicieron de la región un lugar de disputa para el acaparamiento violento de tierras y la acumulación originaria (Peluso \& Lund, 2011; Hall et al., 2015; Ballvé, 2012; Grajales, 2015). Parte del movimiento nacional de paz que pidió un final negociado a la confrontación Estado-faRc (Isacson \& Rojas Rodríguez, 2009), la declaración de San José de Apartadó como la primera comunidad del país inspiró a otras comunidades locales para constituir zonas de paz y humanitarias (Mitchell \& Ramírez, 2009; Rojas, 2007).

Veinte años después, en medio de persistentes ataques pese al acuerdo de $2016^{5}$ entre el Estado y las faRc, la Comunidad de Paz continúa pidiendo que las guerrillas, los paramilitares, el Ejército y la Policía permanezcan fuera de sus veredas, a la vez que se rehúsan a

como el reconocimiento del líder de la Comunidad de Paz de que "somos de sangre indígena, la que llevamos dentro" (Notas de campo, 2012), me llevan a argumentar que el identificante campesino de hecho oculta el proceso por el cual ellos han sido históricamente "des-indigenizados"-esta concepción se la debo a Álvaro Reyes (comunicación personal, 23 de julio de 2015) y a De la Cadena (2000) - No obstante, estos campesinos siguen siendo racializados -marcados con una posición de sujeto de 'menos que humanos' - por su fenotipo y sus políticas autónomas-autonomistas, como el 'indígena salvaje' (Rojas, 2002; Wilderson, 2010), tal como se demuestra por la violencia masiva impuesta contra ellos por el Estado colombiano, tanto antes como después de haber logrado reivindicar su autodeterminación frente a los paramilitares y al Estado al igual quefrente a las guerrillas. En efecto, campesinos mestizos, indígenas y negros afirmaron en la Universidad Campesina que "todos enfrentamos la misma violencia" (Notas de campo, 2013). Por ello, mientras los grupos tienen diferentes prácticas e identidades, la violencia contra campesinos de descendencia indígena y africana demuestra un sujeto racializado análogo. De ahí, considero imperativo señalar que la Comunidad de Paz está conformada principalmente por campesinos descendientes de indígenas (más que de campesinos 'blancos'). 
proporcionar provisiones o información a todos los grupos armados. Ahora, más que ser una simple "zona humanitaria de refugio", definirse a sí mismos como una Comunidad de Paz exige mayores niveles de solidaridad interna y convivialidad. De hecho, en vez de acudir a nociones vagas de "ausencia de guerra" o "tranquilidad", los miembros de la Comunidad de Paz definen la paz activamente como (a) rehusarse a participar en la guerra y (b) construir comunidad. Crean esta paz sembrando en grupos alimentos y cultivos comerciales en tierra común, trabajando por obtener autonomía y soberanía alimentaria por medio de centros agrícolas y granjas autosuficientes, haciendo homenaje a campesinos asesinados, con peregrinaciones de conmemoración hacia los lugares donde ocurrieron las masacres, caminando en solidaridad con campesinos vecinos amenazados por los grupos armados y participando en redes de solidaridad por los derechos humanos y de campesinos indígenas, como la Universidad Campesina. A pesar de haber sufrido repetidos desplazamientos y el asesinato de más de 200 residentes de San José desde 1997 - cerca del 15 \% de su población, la mayoría ejecutados por fuerzas del Estado y paramilitares (Giraldo Moreno, 2010) - , la Comunidad de Paz se extiende ahora a once veredas. Su concepción y su corporalización de la paz, asevero yo, se conjugan para crear un territorio particular: sujetos políticos colectivos generados mediante una serie de prácticas, lugares y valores ${ }^{6}$.

De ahí, que centrarnos en la paz nos permita ver los territorios alternativos, incluso cuando la gente no habla de ellos de esta manera. En efecto, a diferencia de muchas comunidades de

5 Han persistido las amenazas de muerte de militares- paramilitares contra los campesinos de San José hasta 2017 (Comunidad de San José de Apartadó, 2017), incluyendo pintadas en las paredes con spray del acrónimo del grupo paramilitar de las Autodefensas Gaitanistas de Colombia (agc) en las edificaciones dentro del asentamiento de San Josecito en 2016 (Comunidad de Paz de San José de Apartadó, 2016). 
indígenas, negros y campesinos que exigen 'territorios' reconocidos por el Estado (Bocarejo, 2012; Agnew \& Oslender, 2013; Fajardo Montaña, 2002), los líderes de la Comunidad de Paz evitan tales exigencias porque son escépticos con la connotación de territorio que está cargada con la noción de espacio demarcado y forzado por la violencia. Divergir de la tendencia los hace un caso menos obvio de territorialización. De hecho, la Comunidad de Paz está menos enfocada en las políticas que el reciente resurgimiento de algunas organizaciones colombianas que trabajan en la restitución de tierras o la implementación del acuerdo de paz, concentrando más bien su energía en crear una alternativa autónoma a la guerra basada en un lugar dentro de su comunidad y a lo largo de su red de la Universidad Campesina. Sin embargo, esta comunidad es claramente mucho más que un simple conjunto de lugares. Genera una estructura política compleja y espacializada, produciendo también subjetividad. Otros teóricos, por tanto, teorizan sobre el territorio yendo más allá del "área delimitada y controlada" del Estado-nación, pero esta concepción académica tiene implicaciones que superan los grupos étnicos -comunidades indígenas y negras - explorados hasta ahora. Construyendo a partir de estos académicos (Reyes, 2015; Escobar, 2008; Porto Gonçalves, 2006; Liffman, 2011; Delaney, 2005; Haesbaert, 2013) y con el fin de facilitar un cuestionamiento más sistemático de las relaciones sociales y de las subjetividades de procesos políticos divergentes (incluyendo formaciones estatales, así como diferencias entre los movimientos sociales), conceptualizo el territorio como un conjunto no estático de prácticas, lugares y valores ligados a un espacio que genera $-\mathrm{y}$ es generado porsujetos políticos particulares.

La generación de territorio de los movimientos sociales es una práctica corporalizada y espacial, por lo que para entenderlos de esta manera se requiere una metodología comprometida. Mi metodología es lo que denomino 'geografía crítica y de performance'7, 
que integra la teoría crítica y la investigación colaborativa. Desarrollé una investigación etnográfica de 16 meses en Colombia, entre 2011 y 2016, que incluye 49 entrevistas con miembros de la Comunidad de Paz, así como también con militares y miembros de otros movimientos sociales. Esta se basa en mi relación histórica en San José, donde trabajé de 2008 a 2010 como acompañante internacional, una estrategia de seguridad en la cual los defensores de derechos humanos amenazados invitan a "guardaespaldas no armados" (Mahony \& Eguren, 1997) del Norte global a ser testigos de sus luchas y a que las divulguen (Koopman, 2011). Mi investigación es crítica, al reconocer cómo, siendo geógrafo, soy inevitablemente un participante de la construcción de formas particulares de paz y territorio por medio de mi presencia y mis publicaciones (Vasudevan, 2012). Asumo con seriedad esta participación, destacando las voces de mis interlocutores y combinando mi análisis con teorías críticas sobre el territorio, que son necesarias para aprehender la práctica de la Comunidad de Paz. Además, esta es una geografía de performance, puesto que reconozco la manera en que mi cuerpo, como un investigador que toma parte activa en una marcha campesina, realiza una acción de solidaridad internacional. También abordo la entrevista en sí misma, no como una forma de extraer información, pero sí como un espacio de acción de producción de conocimiento en el cual la conversación recíproca permite una

6 Han persistido las amenazas de muerte de militares- paramilitares contra los campesinos de San José hasta 2017 (Comunidad de San José de Apartadó, 2017), incluyendo pintadas en las paredes con spray del acrónimo del grupo paramilitar de las Autodefensas Gaitanistas de Colombia (agc) en las edificaciones dentro del asentamiento de San Josecito en 2016 (Comunidad de Paz de San José de Apartadó, 2016).

7 La razón para mantener y no traducir 'performance', parte integral de performance geography, radica en que en esta palabra se conjuga en un solo término una amplia gama de conceptos inherentes a lo quiere significar el autor cuyas correspondencias en español (performativa, de acción, de interpretación, de desempeño), de manera individual, harían que se perdiera la fuerza global de la lengua original (N. de la T.). 
reflexión continua, además de la clarificación y la generación de teoría (Madison, 2012). Finalmente, presento mis hallazgos con interpretaciones performativas.

Al explorar las prácticas, los valores y los lugares de San José de Apartadó, este trabajo ofrece un método analítico para analizar los diversos ordenamientos políticos del espacio. Doy visibilidad a la territorialidad de su práctica de paz al explorar cómo comprenden la paz, el territorio y la tierra, al igual que algunas de las prácticas de la comunidad: homenajes a las víctimas de las masacres por medio de símbolos con piedras y marchas, caravanas de solidaridad con campesinos vecinos amenazados por los grupos armados, la red de la Universidad Campesina de las comunidades de indígenas-negroscampesinos y las iniciativas de soberanía alimentaria en los centros agrícolas y las granjas autosuficientes. Contrario a la territorialidad estatal de control de tierra y población, que genera sujetos nacionalistas y capitalistas, el proyecto de paz de San José produce un sujeto comunitario y solidario que alimenta una territorialidad relacional entre humanos y la 'naturaleza', así como trasversalmente comunidades que están en resistencia contra la violencia estatalempresarial del acaparamiento de tierras $^{8}$.

\section{Territorio, territorialidad y política}

El territorio se define, por lo general, como un área delimitada controlada por un individuo o un grupo particular, constituida por un "adentro" y un "afuera" (Foucault, 2007; Delaney, 2005; Sánchez Ayala, 2015; Ince, 2012). La forma más reconocida de esta "expresión espacial de poder" es el Estado-nación soberano moderno (Cowen \& Gilbert, 2008, p. 16; Elden, 2009). Como tal, el

8 No obstante, la resistencia local - a pesar del caso tratado acá- no es inevitable ni necesariamente la reacción más común frente al acaparamiento de tierras (Mamonova, 2015). 
territorio está correlacionado con un área o 'lugar', un espacio de significado producido socialmente (Massey, 2005). En consecuencia, la 'territorialidad' se usa con frecuencia para indicar la conexión a o la defensa de un lugar específico, mientras que la 'territorialización' usualmente se refiere al acto de crear territorio tomando el control de ese espacio (Sack, 1986; Agnew \& Oslender, 2013). Los académicos que siguen la etimología moderna de territorio han acuñado su significado como "un lugar ocupado por medio de la violencia del cual as personas tienden a huir" (Connolly, 1994; Elden, 2013). Para Elden (2009), "[...] controlar el territorio es ejercer el terror; retar el control territorial es ejercer el terror" ( $p . x x x$ ). Tales concepciones de territorio, de hecho, están correlacionadas con el actual abordaje que hacen el presidente colombiano Santos y los militares a la 'paz' como un 'orden' obligado de nacionalismo, seguridad militarizada y

9 El enfoque en que se centra este estudio me impide hacer un análisis comprensivo de los diversos imaginarios de paz en medio de la coyuntura del Proceso de Paz colombiano o de los propios acuerdos Estado-farc, temas que exploraré en publicaciones futuras. Sin embargo, mi argumento sobre la territorialidad implícita en el planteamiento de paz del presidente Santos y de los militares requeriría de una selección de citas indicativas; por ejemplo, el discurso nacionalista de Santos es evidente cuando afirma que "La paz total es erradicar la miseria, cuando los colombianos tengan un techo digno y empleo, y que se progresará cuando estén unidos para superar los rencores" (El País, 2014). Pero la naturaleza militarista de dicha paz se refleja en su argumentación de que, finalmente, "el país conseguirá la paz con garrote o con zanahoria" (La Nación, 2014). De una manera similar, el exministro de defensa Juan Carlos Pinzón afirmaba que "En Colombia va a haber paz por la razón o por la fuerza [...] Se requieren unas Fuerzas Armadas fuertes, capaces, haciendo presencia en todo el territorio nacional” (El Tiempo, 2014). Adicionalmente, un oficial del Ejército definía la paz como "El soldado que presta seguridad al hombro con el maestro, el empresario que da trabajo, con el que trabaja la tierra. ¡Pero la tierra es del Estado! Él decide qué hacer con ella. ¡Y la tierra es para explotarla!", decía esto haciendo con las manos el ademán de meter la pala en tierra (comunicación personal, 2014). Así, entonces, él vinculaba el "Proceso de Paz" con el modelo económico extractivista de Santos, en el cual la tierra es algo "para explotar". Estos imaginarios equiparan el enfoque "moderno" o "liberal" a la paz y son ampliamente criticados por académicos por ser Estado-centristas, militaristas y patriarcales (Dietrich, 2012; Daley, 2014). Más aún, reflejan una relación particular con el espacio y la política: una territorialidad de la dominación de la naturaleza y la población sobre las cuales el Estado tiene la máxima autoridad.

9 El Colectivo Agrario Abya Yala trabaja conjuntamente con grupos de campesinos, indígenas y negros en apoyo a sus derechos a territorio. Organiza seminarios, realiza investigaciones y hace publicaciones sobre tierra, territorio y movimientos sociales: (http://www.colecti- voagrarioabyayala.org/). 
una economía extractivista.

Empero, estas definiciones de territorio no son suficientes para captar lo que quieren decir con sus crecientes exigencias de 'territorio', en vez de solo 'tierra', las comunidades indígenas y afrodescendientes que se resisten contra el acaparamiento de tierras en América Latina (Porto Gonçal- ves, 2006; Reyes \& Kaufman, 2011). Estos movimientos sociales luchan por autodeterminación en lugares específicos, pero explican y practican el territorio en un sentido mucho más amplio que solo el lugar físico. Más que "espacios delimitados de control", los grupos hablan del territorio como "vida" (Ballvé, 2013), "entes vivos con memoria" (Ulloa, 2012) o "biodiversidad más cultura" (Escobar, 2008). En un seminario sobre territorio organizado por el Colectivo Agrario Abya Yala en 2013 en Colombia, un representante del pueblo nasa del Cauca cuestionó la lógica estatal de territorio como la demarcación de la naturaleza: "No había que ordenar el territorio sino el pensamiento [...] La naturaleza no tiene ordenamiento [...] Lo que se necesita es ponernos en armonía con la naturaleza”. Más aún, el Colectivo de Sentipensamiento Afrodiaspórico ${ }^{11}$ hace una clara diferenciación entre su concepto de territorio y el del Estado:

La noción de territorio para la población negra de las zonas rurales y la que ha sido desplazada de forma forzosa a las grandes ciudades es distinta a la conceptualización hecha desde las instituciones del Estado. El territorio es concebido como un escenario ancestral indispensable para la producción y recreación de la vida y de la cultura. La tierra no es un recurso para inversión de capital sino el espacio para ser colectivamente (Colectivo de Sentipensamiento Afrodiaspórico, 2015) (énfasis fuera de texto).

Estos imaginarios señalan, por tanto, lo que diferencia a territorio de espacio y lugar. No reducible a un área demarcada, el territorio es una generación más compleja de espacio, más allá de 'lugar', ligado a 
un sitio específico con un significado. En cambio, para estos grupos el territorio significa el diseño de formas particulares de vida y sujetos colectivos por medio de los lugares y valores correspondientes (Reyes, 2015; Cuartas Montoya, 2014; Delaney, 2005; Liffman, 2011, Escobar, 2018). De hecho, como infieren Deleuze y Guattari (1988), la territorialización no es tanto una cuestión de tomar el control sobre un lugar, sino más bien un proceso de unificar cuerpos para conformar una "consistencia" (p. 145) ${ }^{12}$.

Utilizando este marco analítico, podemos señalar los sujetos colectivos generados por la serie de lugares, prácticas y valores del Estado-nación democrático liberal-capitalista: La promoción de una historia nacional, una educación y un empleo supuestamente garantizados, políticas y representación de partidos electorales, los valores de la competitividad y la generación de riqueza, proyectos jerárquicos de desarrollo, incluyendo la minería y la agricultura industrializada y una Policía y unas Fuerzas Armadas que hacen cumplir estos acuerdos a lo largo de un área dada. Al mostrar una territorialidad de control sobre la naturaleza y la población, estos se cohesionan para producir sujetos nacionalistas y capitalistas. En consecuencia, cuando la lideresa del Proceso de Comunidades

${ }^{11}$ El Colectivo de Sentipensamiento Afrodiaspórico está conformado por varias organizaciones afrocolombianas, raizales y palenqueras. Fue fundado en 2013 en la ciudad de Quibdó para trabajar contra el capitalismo y la modernidad, así como también contra la institucionalización y la cooptación del movimiento afrocolombiano (Colectivo de Sentipensamiento Afrodiaspórico, 2015).

12 Merece la pena anotar que, mientras los académicos han utilizado 'desterritorialización' y 'reterritorialización' para describir la acumulación primitiva y la globalización neoliberal (Elden, 2006), Deleuze y Guattari articularon estos conceptos conunaserieaún más amplia deprocesos, incluyendoladesterritorialización psíquica (1993).

13 El Proceso de Comunidades Negras (pcn) es una red de organizaciones afrocolombianas que surgió en la década de 1990 para defender los derechos de las comunidades negras a territorio y cultura (Escobar, 2008). 
Negras (pcn) Francia Márquez Mina (2015) denuncia que hay "helicópteros [militares] bombardeando territorios", significa mucho más que se esté bombardeando el espacio o el lugar. Se trata de que se está bombardeando la serie de prácticas espaciales, lugares y valores que constituyen ese mundo particular que está lleno de vida.

Utilizando este marco analítico, podemos señalar los sujetos colectivos generados por la serie de lugares, prácticas y valores del Estado-nación democrático liberal-capitalista: La promoción de una historia nacional, una educación y un empleo supuestamente garantizados, políticas y representación de partidos electorales, los valores de la competitividad y la generación de riqueza, proyectos jerárquicos de desarrollo, incluyendo la minería y la agricultura industrializada y una Policía y unas Fuerzas Armadas que hacen cumplir estos acuerdos a lo largo de un área dada. Al mostrar una territorialidad de control sobre la naturaleza y la población, estos se cohesionan para producir sujetos nacionalistas y capitalistas. En consecuencia, cuando la lideresa del Proceso de Comunidades Negras (pcn) Francia Márquez Mina (2015) denuncia que hay "helicópteros [militares] bombardeando territorios", significa mucho más que se esté bombardeando el espacio o el lugar. Se trata de que se está bombardeando la serie de prácticas espaciales, lugares y valores que constituyen ese mundo particular que está lleno de vida.

Cuando los grupos indígenas y afro- descendientes mencionados arriba se oponen al extractivismo porque la tierra y el territorio son seres vivos que no deben ser explotados, están expresando una territorialidad alterna - una relación diferente con el espacio y la exterioridad (Raffestin, 2012; Reyes, 2015) - en la que no se trata de controlar la tierra, sino de la relacionalidad con el espacio. Insisten por lograr su autonomía en medio de las amenazas de desplazamiento, bien sea desde los resguardos indígenas, los territorios colectivos negros o las Zonas de Reserva Campesina, administradas colectivamente. Pero la naturaleza subjetiva, material 
y corporizada de estos territorios es bastante diferente de la ideapráctica moderna de "soberanía", constituida por el dominio de un sujeto sobre otras personas y la naturaleza (Reyes \& Kaufman, 2011). Como alternativa a los dualismos modernos de humano/no humano y naturaleza/cultura, los académicos la han considerado "ontologías relacionales" (Blaser, 2010; De la Cadena, 2010; Escobar, 2010; Oslender, 2016) o "paz energética", conformada por una experimentación eterna buscando la armonía y el equilibrio entre todos los seres (Dietrich, 2012).

Esimportanterecordarquelanocióndominantedeterritoriocomo soberanía es un concepto racializado, establecido históricamente por la dominación colonial de los europeos sobre los pueblos indígenas y negros en las Américas y más allá. Equiparar de manera acrítica los proyectos políticos de los actuales campesinos negros e indígenas con soberanía (sub-estatal) es en verdad antitético a la contextualización de las luchas de muchos grupos como no solo anti-neoliberales, sino realmente anti-coloniales (Laing, 2012; Reyes \& Kaufman, 2011). Con certeza, las organizaciones pueden recurrir al lenguaje de soberanía como discurso estratégico y las categorías étnicas en sí están construidas entre sí por interacciones entre activistas comunales, el Estado, académicos e instituciones religiosas, entre otros actores (Wade, 2009; Restrepo, 2002; Bocarejo, 2012; Asher, 2009). Por esta razón, es primordial tener un enfoque analítico más amplio en las prácticas y políticas específicas de un 'territorio' determinado que no lo equipare automáticamente con el poder soberano moderno-colonial o que haga esencial la territorialidad de un grupo particular. Es más, dada la decisión de la Comunidad de Paz de no buscar la creación de una zona de reserva campesina registrada estatalmente en San José de Apartadó -la cual tienen derecho de exigir como campesinos "no- étnicos"-, su divergencia de la tendencia de exigir "territorio" atrae la atención sobre el potencial de las diferentes formas de comprender la 
tierra y el territorio entre las comunidades que hacen resistencia al acaparamiento de tierras.

En el contexto de lo que Dávalos (2011) Ilama 'territorialidades en disputa' entre el neoliberalismo y la resistencia al extractivismo, los académicos han caracterizado estos movimientos sociales latinoamericanos como una 'política otra' (Grupo Acontecimiento, 2012; Denis, 2012) de 'emancipación' (Gutiérrez, 2012): rebasan las elecciones, la representación y la política partidista de la democracia liberal, a la vez que rompen las relaciones de poder de la subyugación, transformando las subjetividades y creando condiciones materiales de vida dignificadas en comunidades autónomas conjugadas en redes de solidaridad. Con certeza, abordar la cuestión agraria (Kautsky, 1988) - la relación entre agricultura y capitalismorequiere que se revelen las subjetividades y las relaciones socioambientales de las territorializaciones tanto capitalistas como no capitalistas o anticapitalistas, lo que no genera inevi- tablemente una relación sujeto-espacio- política de dominación y control. Es obvio que tampoco los procesos territoriales son monolíticos, pero de hecho pueden comprender 'territorialidades que se superponen' (Agnew \& Oslender, 2013) o la 'multiterritorialización' (Haesbaert, 2011) en que se dan diferentes procesos de territorialización en el mismo lugar o la misma persona. Por ejemplo, los miembros de la Comunidad de Paz son un reflejo del territorio nación-Estado (dada su identidad como colombianos), al igual que una territorialidad alternativa de una

autonomía relacional campesina -reelaborando el concepto de Ulloa (2012) de la 'autonomía relacional indígena' - contra la subyugación y el extractivismo.

Esto conduce a un nuevo marco analítico y a una nueva concepción de territorio como un conjunto en movimiento de prácticas, lugares y valores espaciales que genera $-\mathrm{y}$ es generado por- sujetos 
políticos colectivos. Dicho de otra manera, mientras que los lugares son espacios de significado específicos, el territorio es un concepto útil precisamente porque indica una estructuración más compleja del espacio político que el simple espacio o el simple lugar (Reyes, 2015). Tal conceptualización protege de la 'trampa territorial' de equiparar territorio a Estado (Agnew, 1994) porque señala que el Estadonación y el dominio del espacio son solo una forma de territorio y territorialización, respectivamente. Sirve para recordar que la desterritorialización va mucho más allá del mero desplazamiento, es decir, el desalojo de un lugar, mientras que la territorialización implica la creación de un conjunto nuevo de prácticas, lugares, valores y sujetos políticos, o el desarrollo de uno ya existente. Esto permite un análisis más sistemático del tipo de política producida por una serie particular de lugares, prácticas y valores: ¿La política específica genera sujetos individualistas, comunitarios, solidarios y/o competitivos? Y, ¿cuáles son las relaciones entre humanos, no humanos y la tierra-naturaleza? Es entonces en la territorialidad de la Comunidad de Paz de San José de Apartadó en la que me centro.

\section{La Comunidad de Paz: acerca de paz, territorio y tierra}

Empiezo a explorar el proyecto territorial de la Comunidad de Paz examinando cómo entienden ellos la paz, el territorio y la tierra. Vale la pena repetir que las actitudes y las prácticas de paz de la Comunidad de Paz, por ser esta autónoma frente al Estado, surgió como respuesta a la intensa confrontación entre Estadoparamilitares y guerrilla en Colombia a finales de la década de 1990, puesta de manifiesto por desplazamientos masivos y masacres en el Urabá. En mis entrevistas, la mayoría de los miembros definían la paz de dos formas destacadas: (a) rehusarse a participar en la guerra

14 Yaquelosterritoriosen símismos son siempre procesos que están constantemente reconstituyéndose, asevero que diferenciar entre 'territorio' y 'territorialización' es una cuestión de énfasis más que de indicar dinámicas fundamentalmente distintas. 
y (b) trabajo colectivo y construcción de comunidad. Por ejemplo, un miembro manifestaba que la paz "[...] es tener el poder de no ser parte de la guerra, de no colaborar con ningún grupo armado. Poder decidir no ser parte" (comunicación personal, 2013). La paz es, por tanto, cuestión de retirar el apoyo y la legitimidad a los actores de la guerra. También requiere que se construya comunidad, como otro miembro decía de modo sucinto: "La paz es comunidad [...] Juntitos [para que] se puedan hacer las cosas" (comunicación personal, 2013). Refiriéndose a su compromiso con el trabajo comunitario otro afirmaba que "[En] la Comunidad de Paz [...] el trabajo comunitario es todo. Y el trabajo [agrícola] en grupo. [...] Eso es lo que significa la paz" (comunicación personal, 2012). Otro definía también la paz como trabajo colectivo, al describir su transformación subjetiva desde que se había unido a la Comunidad de Paz:

Antes de entrar a la Comunidad, la vida mía era otro, jotro mundo! Era seguir esa ideología capitalista. El tiempo que he estado aquí, he aprendido qué es valorar lo que tenemos, como las tierras, el derecho a la vida [... iLa paz es] todos juntos! Cuando hay un trabajo, ;salen todos! ¡Y siempre! La paz no es hablar. Sino es vivirla (comunicación personal, 2014) (énfasis del entrevistado).

Para dar un sentido más claro de este trabajo comunitario, citaré a un acompañante internacional que narraba la primera vez que acompañaba a lo que se conoce como "el comunitario" ${ }^{15}$, el día semanal de trabajo:

Mi primer acompañamiento fue para un Comunitario, dos días después de mi llegada. Estaban trabajando para arreglar el camino de San José a La Unión. Fueron unas 40 personas, niños, mujeres, un Comunitario donde todos estaban en el mismo equipo. [...] Yo estaba allí alrededor de las 7 de la mañana, y ya [cuatro hombres] estaban allí. En lo que era solo un trozo de barro [...] El trabajo mismo implicó, primero, mover todas las rocas grandes fuera del camino de donde iba a ser [... y después], ir al río para recoger pequeñas piedras, 
colocando las rocas grandes abajo y colocando las pequeñas rocas abajo. Yendo al río, recogiendo sedimentos, como arena aluvial, y luego cubriendo las pequeñas rocas, y luego forrando el camino con rocas más grandes. ¡Y creo que la mayor parte de esto se hizo para el beneficio de los caballos! Eso es un bien público: la comunidad se reunió, y había niños, viejos, y ihabía un chico cuyo trabajo específico era perseguir avispas! Tenía un palo, y [un miembro] le echó gasolina y el niño estaba persiguiendo a las avispas ... y ese era su trabajo específico. Eso fue justo después de que llegué aquí. Me impresionó [...] No solo la comunidad usa ese camino, [hasta] los guerrilleros [... y] los militares usan ese camino [...]. Era un bien público, y beneficiaba a todos [...]. Había como 40 personas, [cada una haciendo] unas 12 horas de trabajo. Y eso fue solamente ese día. La semana siguiente lo hicieron para otras partes (comunicación personal, 2013) (énfasis fuera de texto).

Para decirlo de otra manera, la paz para la Comunidad de Paz no la constituye el acuerdo Estado-faRc. La paz es una práctica diaria de trabajo colectivo, guiada por valores anti-capitalistas y anti-individualistas. Requiere que se cree una alternativa política y económica campesina de autonomía para superar la dependencia que se tiene, para acceder a su bienestar, a los grupos armados, el Estado y la empresa capitalista. En la declaración oficial de la Comunidad de Paz, contemplan otros principios: la justicia (sanciones a los victimarios), la resistencia (el derecho de trabajar en contra del hambre, de la muerte y la injusticia), la solidaridad (sumar "conjuntamente esfuerzos para el bien común") y la libertad ("la capacidad de autonomía de las comunidades y de cada miembro de ellas para tomar sus decisiones autónomamente sin ninguna clase de presión" y el rechazo a la fuerza, como imponen los actores armados) (Comunidad de Paz de San José de Apartadó, 2005, p. 13-

15 Tales jornadas también son llamadas "minga" por ciertas comunidades indígenas en Colombia, como la comunidad nasa, por ejemplo. 
14). Como demuestro más adelante, estas visiones y principios de la paz son centrales al sentido de la Comunidad de Paz de territorio y territorialidad, a su vez muy distintos a los de la "paz" territorial del presidente Santos, como una orden impuesta de control militar, identidad nacional y extractivismo.

No obstante, mientras la "zona de refugio para campesinos no combatientes" de la Comunidad de Paz ha sido reconocida como una nueva territorialidad que desafía la soberanía del Estado (Anrup \& Español, 2011), algunos la interpretan como simplemente otra forma de crear un espacio delimitado, es decir, una sub-soberanía dentro de un Estado-nación controlado por estos agricultores, a la cual los medios de Urabá han tachado de problemática (El Heraldo de Urabá, 2008). Yo alego que esta interpretación es incorrecta. Por el contrario, la Comunidad de Paz rechaza la práctica común de pedir convertirse en "un territorio colectivo registrado por el Estado". En vez de ello, tienen "tierritas comunitarias" y parcelas de miembros individuales por medio de las cuales todos los integrantes tienen acceso a la tierra. Como observaba un acompañante:

\begin{abstract}
Alli hay tierra que técnicamente es propiedad de alguien, pero en realidad nadie es su propietario. Simplemente está allí y la gente puede usarla. En verdad nunca había apreciado qué tan importante podía ser la tierra comunitaria para formar de otra manera una economía, otra sociedad (comunicación personal, 2013).
\end{abstract}

Dicho de otra manera, hay títulos de tierras y la gente sabe de quién son las parcelas y de qué lugar. Pero la práctica socioterritorial es una del acceso y el uso compartidos -como es lo usual a lo largo de las "territorialidades traslapadas" indígenas y negras en la región del Pacífico colombiano (Agnew \& Oslender, 2013)-, lo que constituye parte integral del sujeto colectivo Comunidad de Paz. Más aún, la divergencia de la Comunidad de Paz de la tendencia 
de los grupos marginalizados que exigen "territorio" sancionado por el Estado nos permite analizar los potenciales y las limitaciones del territorio y la tierra como marcos para la resistencia y las políticas autónomas, así como para las prácticas en las que la tierra está material y simbólicamente construida como una forma alternativa de organización anti-Estado.

Dicho de otra manera, hay títulos de tierras y la gente sabe de quién son las parcelas y de qué lugar. Pero la práctica socioterritorial es una del acceso y el uso compartidos - como es lo usual a lo largo de las "territorialidades traslapadas" indígenas y negras en la región del Pacífico colombiano (Agnew \& Oslender, 2013)-, lo que constituye parte integral del sujeto colectivo Comunidad de Paz. Más aún, la divergencia de la Comunidad de Paz de la tendencia de los grupos marginalizados que exigen "territorio" sancionado por el Estado nos permite analizar los potenciales y las limitaciones del territorio y la tierra como marcos para la resistencia y las políticas autónomas, así como para las prácticas en las que la tierra está material y simbólicamente construida como una forma alternativa de organización anti-Estado.

Esto no quiere decir que los miembros de la comunidad nunca hagan referencia al territorio. Algunos utilizan tierra y territorio indistintamente. Por ejemplo, "Cuando nosotros y otras comunidades hablamos de la tierra y el territorio, estamos hablando de la misma cosa" (comunicación personal, 2014). Y una lideresa dijo: "Se lucha por el respeto a la vida, por el territorio, por el respeto de los derechos humanos, una cantidad de cosas que llevan al mismo punto" (comunicación personal, 2012). Mas también explicaba por qué habían rechazado propuestas para declararse territorio colectivo: 
Es que no creemos que es legal, el manejo [...] del territorio. Eso tiene que ver con el subsuelo, el manejo que le da el Gobierno colombiano. Porque ellos van por sus propios intereses. En cambio [...], nosotros no somos exploradores ni vamos a explotar minas [...] La tierra, yo [la] comparo mucho con el cuerpo del ser humano [...]. Si le quita minerales [...], le estamos quitando vida. Como dicen los indígenas, la Madre Tierra. Entonces, sí [...], nosotros hemos pensado en tener terrenos colectivos porque es una manera de fortalecerse más, de poder hacer más resistencia. Pero, los gobiernos son tan traicioneros. Le pueden decir a uno, sí, y aceptan [...] y uno puede tener la tierra colectiva [...]. Pero ellos van cambiando. Tienen la ventana por dónde entrarse (comunicación personal grupal, 2014) (énfasis de la entrevistada).

\section{Otro líder agregaba:}

Meter[se] en lo del territorio [estatal] es peligroso, la ley de extensión y dominio [...]. Los actores armados siempre van a estar en la zona. Necesitan el territorio y que no les vamos a prohibir su paso [...]. No queremos la coca, [por ejemplo, pero] la organización [será] responsable [por la cultivación de otros actores] (Notas de campo, 2013).

Un tercer líder reiteraba el antagonismo entre la comprensión que la comunidad tenía de Estado y los intereses Estado- empresariales en San José de Apartadó:

La tierra es nuestra madre. De ella fuimos tomados. Fuimos hechos del polvo de la tierra. Y ella nos da nuestra alimentación [...] Estas son tierras riquísimas. Y por eso están peleando esta 
tierra y nos quieren sacar porque, por [...] un aire puro, agua pura [...] el carbón, muchos minerales. Oro, etcétera. Y están entregadas ya a una multinacional (Moncada Hurtado, Ossa, \& Caro Morales, 2011) (énfasis del entrevistado).

Estas citas revelan cómo la Comunidad de Paz - concibiendo la tierra como un ser vivo- se esfuerza por tener una relación diferente con la tierra a la que tiene el Estado, lo que es manifestado en su desacuerdo con el extractivismo.

Aunque la Comunidad de Paz es escéptica frente a la idea y la práctica dominantes de territorio del Estado, su insistencia de que los grupos armados permanezcan fuera de sus casas y granjas no debe malinterpretarse como una réplica a escala local de la "soberanía" sobre la tierra y la población tipo Estado. Todo lo contrario, el rechazo de la Comunidad de Paz al extractivismo y a "más demarcación de la tierra" por parte del Estado refleja una forma contrapuesta de territorio y territorialidad. Las diferenciaciones que describen son justamente la razón por la cual necesitamos una concepción más amplia de 'territorialidad' - como la relación entre sujetos y espacio - y de 'territorio' - como un conjunto no estático de prácticas, valores y lugares que generan un sujeto político colectivo-.

\section{Promulgación de una territorialidad alternativa}

Para ilustrar el territorio, y de este otro tipo de territorialidad de la Comunidad de Paz por medio de sus lugares, prácticas y valores, describo ahora cinco elementos centrales de su proceso comunitario: conmemoraciones de las masacres, marchas de solidaridad, redes campesinas de resistencia, centros agrícolas y granjas autosuficientes. 


\section{Conmemoraciones de las masacres}

Guiados por su principio de justicia, dado que persiste la impunidad de parte del Estado frente a los crímenes cometidos contra los campesinos de San José (Giraldo Moreno, 2010), la Comunidad de Paz ejerce su propia justicia. Todos los febreros marchan para conmemorar una masacre cometida en 2005. En las veredas Mulatos y La Resbalosa una operación conjunta de militares y paramilitares decapitó y desmembró los cuerpos de ocho campesinos, incluyendo al fundador de la Comunidad de Paz, Luis Eduardo Guerra, y tres niños. Anualmente la Comunidad marcha a los lugares de los hechos, vuelve a narrar esos hechos y pinta piedras con los nombres de las víctimas. Se les unen otras comunidades campesinas, grupos de derechos humanos, periodistas, acompañantes internacionales y académicos de Colombia y otros países. Esta es una forma de justicia conmemorativa, a diferencia de la justicia criminal o retributiva del Estado.

Estas prácticas y estos lugares de memoria son fundamentales para su territorio y su política más amplia: contra los mantras represivos de "perdonar y olvidar" que pueden impedir la paz (Gómez Muller, 2008), los campesinos de San José alimentan implícitamente la relacionalidad con los muertos (Gómez-Correal, 2015), mediante un "regreso difícil" (Simon, Rosenberg \& Eppert, 2000) al evocar la presencia y los valores de los fallecidos con nombres, historias y piedras. Por medio de las conmemoraciones, los miembros de la Comunidad reafirman su ética contra la violencia retaliatoria, a la vez que refuerzan su cohesión y su compromiso organizacionales. De hecho, los miembros afirman que "la memoria es la fuerza de nuestra resistencia" 16 .

16 Para una exploración más exhaustiva del papel de la memoria en el proyecto de paz de San José, ver Courtheyn (2016). 


\section{Marchas de solidaridad}

Además de la conmemoración anual de la masacre de Mulatos, la Comunidad de Paz realiza otras marchas grandes cada año. En octubre de 2013, debido a amenazas y secuestros de los paramilitares que desplazaron muchas familias de la vereda contigua Rodoxalí, la comunidad organizó una marcha para confrontar a los paramilitares y las fuerzas del Estado operando allí, a pesar de no ser esta un asentamiento de la Comunidad de Paz. Como en las conmemoraciones, delegados de muchos países participaron, incluyéndome. Cuando llegamos a Rodoxalí encontramos solo unas pocas familias que seguían allá. La mayor parte del pueblo estaba abandonado. En una casa, ropa abandonada se podría en la humedad puesto que con frecuencia los pequeños agricultores únicamente pueden irse con lo puesto y llevarse con- sigo animales grandes que sirven como sus ahorros- cuando son expulsados a la fuerza. Contra la lógica antropocéntrica de que solo cuentan las vidas humanas, una integrante de la Comunidad de Paz se lamentaba diciendo: "Miren los patitos y pollitos, pobrecitos, rebuscando comida". Y continuó diciendo:

Caminar y visitar le hace recordar todo lo que uno ha vivido. Se piensa, "Pasó lo mismo acá que donde nosotros [durante el desplazamiento masivo que sufrimos] en 1997?" Y si esos tiempos volverán ahorita [...] Antes uno decía, cuando se escuchaba de una masacre, "Eso pasó lejos, no llega por aquí". Pero sí. [... Hay que] estar en solidaridad (Notas de campo, 2014).

En otras palabras, estas marchas sirven para la auto-reflexión acerca de la guerra-pasada y presente- y para generar solidaridad entre las diferentes organizaciones campesinas y de derechos humanos.

Cuando marchamos para buscar a los paramilitares, estos habían huido a las montañas. El sacerdote jesuita y abogado Javier Giraldo 
- que ha acompañado a la Comunidad de Paz desde que fue fundada y es uno de los principales defensores de derechos humanos en Colombia - dijo: "No han sido capaces de enfrentar y constatar su verdad con la nuestra". Solo cuando ya nos habíamos ido, los paramilitares "hicieron sentir" su presencia disparando balas al aire desde la distancia (Comunidad de Paz de San José de Apartadó, 2013). Al partir de Rodoxalí, los campesinos que todavía seguían viviendo allí nos dijeron que se habían sentido acompañados y nos invitaron a visitarlos en el futuro. En nuestra posterior reunión informativa de retroalimentación, delegados de las comunidades indígenas afirmaron: "Caminamos la palabra" de paz al marchar en solidaridad con esos campesinos. La Comunidad de Paz manifestó al inicio de la marcha: "No dejaremos a nadie atrás, a pesar de estar en una zona de guerra" (Notas de campo, 2013). Y sostengo que en la marcha en sí se creó "paz como comunidad" al habernos ayudado mutuamente a cruzar ríos.

Esta movilización muestra que el territorio -más que estar limitado a un lugar - es una práctica en movimiento a través del espacio. También señala una territorialidad diferente de aquella de los paramilitares y el Estado. Si la Comunidad de Paz hubiera estado preocupada en "controlar el espacio y la población" no marcharía en solidaridad con aquellos que no son miembros, como los de Rodoxalí, o pretenderían imponer las reglas de su comunidad a estos campesinos vecinos. En cambio, estas caravanas reafirman ciertos valores y crean sujetos políticos solidarios como parte del territorio alterno que producen.

\section{Redes de resistencia campesina}

Después de la marcha de Rodoxalí, la Comunidad de Paz celebró una sesión de la Universidad Campesina de Resistencia. Estos encuentros iniciaron en 2004 en la aldea Arenas Altas de la Comunidad de Paz, luego de que un año antes se hubiera conformado 
la Red de Comunidades en Ruptura y Resistencia. Esta red se reúne periódicamente en diferentes lugares para compartir conocimiento acerca de soberanía alimentaria, los derechos humanos, estrategias de medios de comunicación comunitarios y prácticas autónomas de atención en salud. Parafraseando a Javier Giraldo (Notas de campo, 2013), el encuentro es una alternativa a la universidad tradicional, dados sus claros objetivos: no tratar el conocimiento-educación como algo mercadeable en que se paga por adquirir conocimiento o se vende un diploma como mercancías, darle la vuelta al esquema de profesores y estudiantes haciendo que todos y todas puedan contribuir, centrarse en las necesidades de los grupos más afectados, es decir, campesinos indígenas y afrodescendientes y rotar entre estas comunidades en vez de tener un lugar fijo.

En la sesión de 2013, un grupo seleccionó plantas que la gente sabía que tenían propiedades medicinales. Las procesaron haciendo polvos y cremas. Un miembro de la Comunidad de Paz definió la universidad utilizando la metáfora de las abejas contra las moscas:

Siempre usted ve a toda hora a la abeja pegada a las flores. De allí extrae su néctar. En seguida llevando a sus panales. Alli van a fabricar su miel. ¿Para qué sirve la miel? Para muchísimo. Es remedio [... Otras comunidades] nos traen cosas nuevas y buenas para que aprendamos. Y también llevan de aquí para allá [...] Hacer fabricaciones de las pomadas para los dolores. Y el talco para las pecuecas. La planta solar en la parte tecnológica. La parte agroalimentaria. [...] Ese compartimiento, hermanamiento [...] es dulce [...] En lugar de ser moscas [...] llevando y trayendo pura suciedad (comunicación personal, 2014).

Por tanto, esta universidad está organizada para producir conocimiento tangible y productos útiles para las necesidades de

16 Los encuentros de la Universidad Campesina fuera de San José de Apartadó han tenido lugar también en San Vicente del Caguán y la Sierra Nevada de Santa Marta. 
la gente y para el bienestar. Más aún, al igual que las caravanas de solidaridad, mucho de lo que constituye la Universidad Campesina está en cómo se nutre la fraternidad en esos espacios, esto es, la clase de prácticas y valores del espacio que conforman dicho territorio como alternativa a la dependencia de la asistencia social del Estado y de los mercados capitalistas: colaboración, horizontalidad y anticomercialismo. Los miembros de la Comunidad de Paz definen la paz como "comunidad" y estas redes de solidaridad crean un territorio comunitario de paz que trasciende las demarcaciones étnicas o religiosas limitadas a un lugar (Federici, 2010). De nuevo, se vuelve a demostrar cómo este no constituye un territorio que es un "área" física, incluso si los encuentros que rotan entre las diferentes comunidades son una de sus prácticas fundamentales de este territorio alternativo.

\section{Centros agrícolas}

En los centros agrícolas la Comunidad de Paz pone en práctica lo que ha aprendido de su red. En la vereda La Unión preservan una variedad de plantas medicinales y cultivos de alimentos, realizan talleres, tienen una librería y una valla prohíbe explícitamente la explotación de minerales. Con conocimientos de arquitectura aprendidos de las comunidades indígenas construyeron kioscos circulares con material local como lugares de encuentro. Un cambio en que se distancian de las edificaciones cuadradas de concreto, estas construcciones reflejan los objetivos y los principios de la Comunidad de Paz: la soberanía alimentaria necesita de

lugares para cultivar las cosechas y de espacios para la discusión colaborativa. Y para generar un sujeto comunitario se tienen que crear lugares que cultiven la horizontalidad, en donde la gente se pueda sentar en un círculo mirándose todos a la cara. 
Con el apoyo de la Universidad Campesina, por ejemplo, procesan su propia panela. El coordinador del centro agrícola describe la iniciativa:

Me da tanta felicidad sacar la miel de caña. Ha habido muchas dificultades. La gente decía: "Que no, muy difícil. No van a sacar miel ni panela". Pero algunos chuchitos me decían: "iSí! ;Eso sirve! Trabajé la caña mucho desde niño". Y arrancamos. Los indígenas vinieron aquí para mostrarnos cómo hacer panela. La primera se perdió. Mucha gente, hay que mostrarles que sí las cosas son posibles. Que vean, porque no creen: "Yo no la tomaré, no". La gente ya está feliz, sacando panela. Tiene un buen sabor (comunicación personal, 2012) (énfasis del entrevistado).

La mayor parte del consumo de panela en La Unión está cubierta ahora con lo producido en su trapiche.

Las acciones para contrarrestar los monocultivos se fundan en la concepción de que la tierra es un ser vivo, como lo explicaba un miembro:

Es que el campesino quiere que el cultivo sea de una cosa, y ya. Pero yo les voy diciendo: "Si una persona va comiendo bananos solamente, le hace mal a la salud. Pues, para la tierra es lo mismo. Hay que sembrar muchas cosas y va alimentando la tierra" (Notas de campo, 2013).

Como otros miembros de la Comunidad de Paz, expresó una relación comunicativa con la tierra. Esta no es meramente un objeto inerte, sino unservivo que requiere dealimentoy deuna "dietavariada y saludable", justo como los humanos. Sin usar el lenguaje de los "seres tierra" (De la Cadena, 2010) ni practicar rituales espirituales para conectar con la Madre Tierra (Vachon, 2011), la manera en que conciben estos campesinos la tierra es, no obstante, similar a muchos grupos indígenas en las Américas. Más aún, la cita indica cómo la pequeña agricultura no es necesariamente "sostenible": una territorialidad relacional es producto de la práctica política, 
no la "esencia" de pueblos particulares. En verdad, equiparar de modo automático etnicidad con una territorialidad específica puede espacializar peligrosamente y delimitar la diferencia (Bocarejo, 2012). Pero al centrarnos en las prácticas podemos ver cómo el centro agrícola de La Unión es un lugar dentro de un territorio más amplio en el que se cultiva esta relacionalidad y se sustenta su forma de paz como autodeterminación.

\section{Granjas autosuftcientes}

Unos pocos miembros están trabajando para crear granjas familiares totalmente autosuficientes. En seguida describo de manera extensiva un recorrido por una de esas granjas (Notas de campo, 2013). El coordinador de la granja comenzó por darle crédito a los años de resistencia y de las redes de solidaridad de la Comunidad de Paz que le permitieron visitar otras comunidades dentro y fuera de Colombia, en especial a comunidades indígenas con quienes había intercambiado semillas e ideas.

Explicaba el fundamento de la granja de hacerla "autosuficiente para una familia, la cual, afirmo en decir, no existe. [...] Que tengamos alternativas [y] nuestra propia alimentación". Comparaba esto con la lógica campesina prevalente en el área:

Unos piensan en y van al mercadeo, pero por eso no es. Siempre he dicho que las comunidades necesitan pensar en una soberanía alimentaria. Hay que cambiar la mentalidad, la mentalidad de todos, poco a poco [...] Esta zona es cacaotera y mucha gente vive del mero cacao. Lo venden y con eso compran todo el resto. El año pasado dio mucho. Pero este año no hay. Yo también, pasé tres años en el proyecto del banano primitivo y [en ese entonces] había buen precio. Pero eso se acabó [por no poder mantener el negocio por los envíos] y volví al cacao. Pero hay que aprender de esas experiencias y tener otra estrategia. 
Afirmaba que la soberanía alimentaria y la autonomía han sido especialmente importantes, dada la historia de violencia de Estado, al igual que la toxicidad y la dependencia en la coyuntura neoliberal que aumentan cada vez más:

Ahora están los tratados de libre comercio y el problema de los transgénicos. Por las multinacionales, los alimentos [están] cada vez más envenenados [...] Hay que pensar y actuar a ser diferente a un Estado. A un Estado que todo el tiempo nos ha atropellado, nos ha matado, nos ha desplazado. Quiere exterminarnos [...] Quieren someter a toda la humanidad. Los grandes capitalistas. Los que manejan todo este planeta [...] En las ciudades, hay que comprar todo. Es ser esclavo de ellos.

Cuando empezamos el recorrido en la casa señaló un ejemplo de autosuficiencia:

Mire, el techo de la casa. La paja es bien sencilla, yo la tengo sembrada aquí mismo. No voy a tener ningún problema de estar pensando, "Tengo que comprar [...]", ;no! Esto es una alternativa. No me va a costar nada. Además, es una tradición de nuestros abuelos. Es una alternativa porque un techo de esos es lo más fresco que puede haber. Puede estar el sol que sea y uno se duerme.

Respondí diciendo:

Es tan interesante, la tecnología de los abuelos como una "alternativa". La tecnología capitalista ha llegado a ser tan dominante, en que hay que comprar todo, para este techo sostenible se convierte en una "alternativa", icuando era lo normal en el pasado! 
Contestó mientras seguíamos caminando:

Y me encanta. Esto es bore. Para el cuido de los peces y tengo ese tajo sembrado ahí. Es una comida especial que les gusta [...] Esta planta es de los indígenas del Cauca, la traje de allá, para cuidar gallinas y pollos. Es un alimento especial [...] Mire este gallinero portátil. Después de un tiempo, se lo mueve y ahí se siembra algo, porque la gallina abona la tierra. ¡Sencillo y útil! [...] Por arriba voy a sembrar, para ir rotando: yuca, arroz, maíz y frijol [...] Esta es la huerta [...] Penca sábila, café, lulo y plantas medicinales [...] ; Mire cómo huele el curanto!

No pudo contener su entusiasmo al expresar el amor por la vida rural que sigue conduciendo la lucha de la Comunidad de Paz, así como su relación con los seres no humanos: "Me encanta el campo. Me gusta cultivar. Mire los animales silvestres que andan por ahí. Les siembro comida también, frutales, para que se diviertan y venga a que canten. Yo me divierto con ellos". De manera similar a lo que sienten otros miembros acerca de vivir con otros seres en la naturaleza, esto refleja una relación no instrumentalista con el "medio ambiente": el objetivo es la reproducción recíproca en que humanos, animales y plantas se alimentan entre sí.

Él ve la granja como un lugar de inspiración para otros campesinos que necesitan no volverse dependientes de los cultivos comerciales, los mercados o de fundaciones externas. Pero esto requiere pensamiento creativo y estratégico:

Me gusta hablar de un espacio tan pequeño, pero sostenible para una familia. Aqui se ve que nadie está metiendo plata. Yo quiero mirar qué es lo que una familia, usando sus propios recursos, es capaz de hacer, sin esos dineros que a veces financian proyectos y a veces tanto daño, porque hay plata de por medio [...]. Con este proyecto mucha gente va a darse cuenta de que no se necesita tanta cantidad de tierra para poder sobrevivir, incluso en medio de un conflicto de estos. Necesitamos poco espacio, pero necesitamos saber trabajar. Y saber pensar. 
Al fortalecer la autonomía comunitaria, esta granja facilita la independencia de la Comunidad de Paz de - y el rechazo a - guerrilla, paramilitares y las Fuerzas Armadas. De modo similar a cómo San José de Apartadó ha sido inspirador para otros movimientos de paz en Colombia y más allá de las fronteras (García de la Torre et al., 2011; Nieri, 2007), esta granja autosuficiente se encuentra destinada a inspirar a otros miembros en el interior de la comunidad y además a otros campesinos colombianos. Tales alternativas son especialmente importantes durante el "Proceso de Paz" de Colombia como posibilidades para jóvenes en riesgo de quedar marginados y desempleados después del proceso de desarme.

Es sorprendente que estas granjas se mantengan relativamente invisibles tanto para los académicos que estudian la Comunidad de Paz (Aparicio, 2012; Burnyeat, 2018; Masullo, 2015), como en sus propios comunicados de prensa en su página web (www. cdpsanjose.org). Por ello, apreciar las capas productivas de este territorio específico requiere compromiso con su "transcrito oculto de resistencia" (Scott, 1990). Mientras observábamos la granja, el coordinador concluyó:

Es un sitio escondido. Es como un lugar secreto, porque no se lo ve [de otros caminos o fincas]. Solamente se ve cuando se viene aquí. Pero si uno viene solo, no ve todo lo que le he mostrado. Pero cuando empieza a ver todo lo que hay, se ve bastante. Es como entrar en otro mundo.

Argumento que la misma clase de in- visibilidad caracteriza la paz alternativa y el territorio alternativo en comunidades como San José de Apartadó: un abordaje más amplio y más sistemático a la conceptualización de territorio nos permite ver la complejidad de las diversas producciones de espacio político. Si reducimos el territorio a un "lugar" o un área delimitada controlada por cierto grupo podemos pasar por alto las relaciones sociales y los sujetos políticos generados por dicho conjunto de lugares y prácticas. Si el territorio 
puede reducirse a "lugares ocupados por medio de la violencia de los cuales las personas tienden a huir" (Connolly, 1994) -como la paz como "orden y seguridad" del Estado-, entonces el término obviamente no será de los que guíe una política emancipatoria. Sin embargo, por medio de las granjas autosuficientes, las redes campesinas, las marchas de solidaridad y las conmemoraciones de las masacres, la Comunidad de Paz crea de forma simultánea otro tipo de paz y otro tipo de territorio.

\section{Conclusión}

La formación territorial de la Comunidad de Paz es visible cuando analizamos el sujeto político que genera y es generado por sus series de prácticas, lugares y valores: a) lugares de memoria por medio de homenajes con piedras y conmemoraciones en los sitios de las masacres, b) el día semanal de trabajo para la comunidad, c) los encuentros de la Universidad Campesina, d) centros agrícolas y granjas autosuficientes, e) lugares circulares de encuentro y f) valores de resistencia, justicia y comunidad. Creada por la práctica rutinaria más que por ser alguna clase de "esencia" campesina o étnica, esta formación territorial los cohesiona para cultivar un sujeto político colectivo y solidario que es un sujeto relacional que busca no explotar el "medio ambiente" o separar los muertos de los vivos. La Comunidad de Paz de San José muestra entonces un conjunto fluido y siempre cambiante de lugares y prácticas que produce una política colectiva en proceso.

Para el Estado colombiano, la "paz" es una condición alcanzada en que su punto terminal de territorio es el control de la tierra y la población. A las manifestaciones de los movimientos sociales sobre tierra, territorio y autonomía el Estado ha reaccionado con represión, dado que el Estado moderno interpreta tales movimientos como "un plan rival para dividir en vez de ver la división en sí misma como el problema" (Elden, 2013, p. 1). La Comunidad de Paz tiene una 
práctica más fluida tanto de la paz como del territorio, proclamando ambos como un proceso en constante despliegue, sin punto final. Esta territorialidad no está constituida por división y violencia sino, por el contrario, por la relacionalidad con el espacio, en donde comunidad y espacio están integrados por tierra común, grupos de trabajo y redes campesinas de derechos humanos que generan sujetos políticos emancipatorios, comunitarios y solidarios. En Colombia, en la coyuntura actual del "Proceso de Paz", la Comunidad de Paz y la Universidad Campesina demuestran cómo los "territorios de paz" deben contener formaciones espaciales y políticas más complejas que vayan más allá de la ausencia de violencia retaliatoria. Estas son ejemplos de territorialidades de paz ya existentes que demuestran lo que las comunidades pueden hacer sin tener que esperar lo que los actores armados o del Estado harán en un contexto post-acuerdo. En efecto, explorar esta territorialidad campesina constituye una apertura hacia teorizaciones más directas de la "paz" en la academia futura.

La Comunidad de Paz demuestra cómo las comunidades representan diferentes geografías y territorios sin privilegiar necesariamente la terminología de "territorio". Por el contrario, su territorialidad surge por medio de discursos y prácticas de paz. Al rechazar la noción dominante de territorio como "espacio delimitado y controlado", la Comunidad de Paz de hecho permite una conceptualización más amplia de territorio. Nos permite ocuparnos de los proyectos territorio-políticos de una gama de comunidades más allá de aquellas que tienen una identidad étnica positiva o que exigen territorio. Incluso allí donde las organizaciones como la Comunidad de Paz rechazan el lenguaje de "territorio", el término territorio sigue siendo útil precisamente porque se refiere a un diseño político específico: no diseño en el sentido moderno limitado de un diseñador que crea algo fuera de sí mismo, sino un "diseño ontológico autónomo" (Escobar, 2018) que se da mediante prácticas, 
valores y lugares que se cohesionan para generar un sujeto político colectivo emancipatorio.

\section{Bibliografía}

Agnew, J. (1994). The territorial trap: The geographical assumptions of international relations theory. Review of International Political Economy, 1(1), 53-80.

Agnew, J., \& Oslender, U. (2013). Over- lapping territorialities, sovereignty in dispute: Empirical lessons from Latin America. En W. Nicholls, B. Miller, \&

J. Beaumont (eds.) Spaces of contention: spatialities and social movements (pp. 121-140). Aldershot: Ashgate.

Anrup, R., \& Español, J. (julio-diciembre, 2011). Una Comunidad de Paz en conflicto con la soberanía y el aparato judicial del Estado. Diálogos de Saberes 35, 153-169.

Aparicio, J. R. (2012). Rumores, residuos y Estado en "la mejor esquina de Sudamérica": Una cartografía de lo "humanitario" en Colombia. Bogotá: Ediciones Uniandes.

Asher, K. (2009). Black and green: AfroColombians, development, and nature in the Pacific lowlands. Durham: Duke University Press.

Ballvé, T. (2012). Everyday state formation: Territory, decentralization, and the narco landgrab in Colombia. Environment and Planning D: Society and Space, 30(1), 603-622.

Ballvé, T. (2013). Territories of life and death on a Colombian frontier. Antipode 45(1), 238-241.

Bebbington, A. (2009). Latin America: Con- testing extraction, producing geographies. Singapore Journal of Tropical Geography, 30(1), 7-12. 
Blaser, M. (2010). Storytelling globalization from the Chaco and beyond. Durham: Duke University Press.

Bocarejo, D. (2012). Emancipation or enclosement? The spatialization of difference and urban ethnic contestation in Colombia. Antipode 44(3), 663-683.

Burnyeat, G. (2013). On a peak in Darien: Community peace initiatives in Urabá, Colombia. Journal of Human Rights Practice, O(O), 1-11.

Burnyeat, G. (2018). Chocolate, Politics and Peace-Building: An Ethnography of the Peace Community of San José de Apartadó, Colombia. London: Palgrave Macmillan.

Colectivo de Sentipensamiento Afrodiaspó- rico (2015). Sentipensar la paz. Una paz pacífica es posible. Cali: Colectivo de Sentipensamiento Afrodiaspórico. Recuperado de https://www.google.com/ url?sa= $t \& r c t=j \& q=\& e s r c=s \&$ source $=w \quad$ eb\&cd $=1 \& v e d=0$ ahUKEwjZtJHfs7Q AhXG6iYKHRpOCsOQFggcMAA\&u rl=http:// poderyunidadpopular.org/index.php/noti/item/download/6_998c3c5 d3c2a45997994e8d9f772e891\&usg=AFQjCNGef37EanvyUFUKO T-h3LcweUpQWw\&sig2=7Dy

Comunidad de Paz de San José de Apartadó (2005). Nuestros principios en la Comunidad de Paz en San José de Apartadó. En Noche y niebla. Caso tipo n ${ }^{\circ}$ 6. Comunidad de Paz de San José de Apartadó (pp. 13-15). Bogotá: Centro de Investigación y Educación Popular (cinep).

Comunidad de Paz de San José de Apartadó (2013). Sin armas en búsqueda de un ejército de asesinos armados. Recuperado de http:// historico.cdpsanjose.org/?q=node/281/

Comunidad de Paz de San José de Apartadó (2016). Se incrementa asedio paramilitar contra nuestra Comunidad de Paz. Recuperado de http://www.cdpsanjo- se.org/node/70 
Comunidad de Paz de San José de Apartadó (2017). Viviendo bajo el terror y la zozobra paramilitar. Recuperado de http://www.cdpsanjose. org/node/90 Connolly,W. E. (1994). Tocqueville, territory and violence. Theory, Culture \& Society, 11(1), 19-40.

Courtheyn, C. (2016). "Memory is the strength of our resistance": an "other politics' through embodied and material commemoration in the San José Peace Community, Colombia. Social \& Cultural Geography, 17(7), 933-958. Courtheyn, C. (2018). Peace geographies: Expanding from modern-liberal peace to radical trans-relational peace. Progress in Human Geography, 42(5), 741-758. Doi: https://doi. org/10.1177/0309132517727605

Cowen, D., \& Gilbert E. (2008). The politics of war, citizenship, territory. En D. Cowen, \& E. Gilbert (eds.). War, citizenship, territory (pp. 1-30). New York: Routledge.

Cuartas Montoya, G. (2014). La guerra como práctica de adecuación de los lugares. Criterio Jurídico Garantista, 6(10), 12-33.

Daley, P. (2014). Unearthing the local: Hegemony and peace discourses in Central Africa. En F. McConnell, N. Megoran, \& P. Williams (eds.), Geographies of peace (pp. 66-86). Nueva York: I.B. Tauris.

Dávalos, P. (2011). La democracia disciplinaria: el proyecto posneoliberal para América Latina. Bogotá: Ediciones Desde Abajo.

De la Cadena, M. (2000). Indigenous Mestizos: The politics of race and culture in Cuzco, Peru, 1919-1991. Durham: Duke University Press.

De la Cadena, M. (2010). Indigenous cosmopolitics in the Andes: Conceptual reflections beyond 'politics'. Cultural Anthropology, 25(2), 334-370. 
Delaney, D. (2005). Territory: A Short Introduction. Malden: Blackwell Publishing.

Deleuze, G., \& Guattari, F. (1983). Anti-Oedipus: Capitalism and schizophrenia. Minneapolis: University of Minnesota Press.

Deleuze, G., \& Guattari, F. (1988). A thousand plateaus: Capitalism and schizophrenia. Minneapolis: University of Minnesota Press.

Denis, R. (2012). The birth of an "other politics" in Venezuela. South Atlantic Quarterly, 111(1), 81-93.

Dietrich, W. (2012). Interpretations of peace in history and culture. Nueva York: Palgrave Macmillan.

El Espectador (26 de agosto de 2014). "Somos amigos de la inversión extranjera”: Santos. El Espectador. Recuperado de http://www. elespectador.com/noti-cias/politica/somos-amigos-de-inversionextranjera-santos-articulo-512951

El Heraldo de Urabá (mayo de 2008). ong quieren formar república independien-te. El Heraldo de Urabá.

El País (4 de marzo de 2014). "Vamos por la paz total": dijo Santos al inscribir su candidatura en la Registraduría. El País. Recuperado de http://www.elpais. com.co/elpais/elecciones/noticias/juan-manuelsantos-y-vargas-lleras-inscriben-su candidatura-presidencia

El Tiempo (4 de mayo de 2014). "El ciudadano necesita ver que se castiga a los que violan la ley": Pinzón asegura que si hay un escenario de paz es porque las Fuerzas Armadas lo hicieron posible. El Tiempo. Recuperado de http://m. eltiempo.com/politica/justicia/el-ciudadanonecesita-ver-que-se-castiga-a- los-que-violan-la-ley/13928377

Elden, S. (2006). The state of territory under globalization: Empire and the politics of reterritorialization. Thamyris/Intersecting, 12, 47-66. 
Elden, S. (2009). Terror and territory: The spatial extent of sovereignty. Minneapolis: University of Minnesota Press.

Elden, S. (2013). The birth of territory. Chicago: The University of Chicago Press. Escobar, A. (2008). Territories of difference: Place, movements, life, redes. Durham:Duke University Press.

Escobar, A. (2010). Latin America at a crossroads: Alternative modernizations, post-liberalism, or post-development? Cultural Studies, 24(1), 1-65.

Escobar, A. (2018). Designs for the pluriverse. Durham: Duke University Press.

Fajardo Montaña, D. (2002). Para sembrar la paz hay que aflojar la tierra: Comunidades, tierras y territorios en la construcción de un país. Bogotá: Universidad Nacional de Colombia.

Fanon, F. (2004). The wretched of the Earth. Nueva York: Grove Press.

Fanon, F. (2008). Black skin, White masks. Nueva York: Grove Press.

Federici, S. (2010). Feminism and the politics of the commons in the era of primitive accumulation. En Team Colors Collective (ed.). Uses of a whirlwind: Movement, movements, and contemporary radical currents in the United States (pp. 283-293). Oakland: AK Press.

Foucault, M. (2007). Questions on geography. En J.W. Crampston, \& S. Elden (eds.). Space, Knowledge and Power: Foucault and Geography (pp. 173-182). Burlington: Ashgate Publishing Company.

García de la Torre, C. I., Aramburo Siegert, C. I., Barajas, D. M., Valderrama, D., \& Espinosa, N. (2011). Geografías de la guerra, el poder y la resistencia: Oriente y Urabá antioqueños 1990-2008. Bogotá: Centro de Investigación y Educación Popular (cinep). 
Giraldo Moreno, S. J. (2010). Fusil o toga, toga y fusil: El Estado contra la Comunidad de Paz de San José de Apartadó. Bogotá: Editorial Códice.

Goldberg, D. T. (2009). The threat of race: Reflections on racial neoliberalism. Mal den: Wiley-Blackwell.

Gómez Correal, D. M. (2015). Of love, blood and the belly: The politicization of intimate ties of caring and belonging in Colombia (Tesis doctoral, University of North Carolina, Chapel Hill, usa).

Gómez Muller, A. (2008). La reconstrucción de Colombia: Escritos políticos. Medellín: La Carreta Editores.

Grajales, J. (2015). Land grabbing, legal contention and institutional change in Colombia. The Journal of Peasant Studies, 42(3-4), 541-560.

Grupo Acontecimiento (2012). The affirmation of another politics of emancipation. South Atlantic Quarterly, 111(1), 29-49.

Gudynas, E. (2015). Extractivismos: Ecología, economía y política de un modo de entender el desarrollo y la naturaleza. Cochabamba: cedib.

Guha, R. (1983). Elementary aspects of peasant insurgency in Colonial India. De Ihi: Oxford University Press.

Gutiérrez, R. (2012). The rhythms of the Pachakuti: Brief reflections regarding how we have come to know emancipatory struggles and the significance of the term social emancipation. South Atlantic Quarterly, 111(1), 51-64.

Haesbaert, R. (2011). El mito de la desterritorialización. México: Siglo xxi. Haesbaert, R. (2013). El mito de la desterritorialización: del fin de los territorios a la multiterritorialidad. Cultura y Representaciones Sociales, 8(15), 9-42. Hall, R., Edelman, M., Borrás, S. M., Scoones, I., White, B., \& Wolford, W. (2015). Resistance, acquiescence or in- 
corporation? An introduction to land grabbing and political reactions "from Below". The Journal of Peasant Studies, 42(3-4), 467-488.

Ince, A. (2012). In the shell of the old: Anarchist geographies of territorialisation. Antipode, 44(5), 1645-1666.

Isacson, A., \& Rojas Rodríguez, J. (2009). Origins, evolution, and lessons of the Colombian peace movement. En V. M. Bouvier (ed.). Colombia: Building peace in a time of war (pp. 19-37). Washing- ton: United States Institute of Peace.

Kautsky, K. (1988). The agrarian question, Vol. 1. Londres: Zwan Publications.

Koopman, S. (2011). Alter-geopolitics: Other securities are happening. Geofo- rum, 42(3), 274-284.

La Nación (7 de febrero de 2014). Juan Manuel Santos: "Colombia conseguirá la paz, con garrote o con zanahoria”. La Nación. Recuperado de http://www.lanacion.com.ar/1662215-juan-ma- nuel-santoscolombia-conseguira-la- paz-con-garrote-o-con-zanahoria

Laing, A. F. (2012). Beyond the zeitgeist of "post-neoliberal" theory in Latin America: The politics of anti-colonial struggles in Bolivia. Antipode, 44(4), 1051-1054.

Liffman, P. M. (2011). Huichol territory and the Mexican nation: Indigenous ritual, land conflict, and sovereignty claims. Tucson: University of Arizona Press.

Madison, D. S. (2012). Critical ethnography: Method, ethics, and performance. $2^{a}$ ed. Los Angeles: Sage Publications.

Mahony, L., \& Eguren L. E. (1997). Unar- med bodyguards: International accompaniment for the protection of human rights. West Hartford: Kumarian Press. Mamonova, N. (2015). Resistance 
or adaptation? Ukrainian peasants' responses to large-scale land acquisitions. The Journal of Peasant Studies, 42(3-4), 607-634.

Márquez Mina, F. (2015). Víctimas en el Proceso de Paz. Ponencia presentada en el simposio The Challenges of the Current Peace Negotiation Process in Colombia: Multiple Perspectives. Cha- pel Hill: University of North Carolina. Recuperado de https://www.youtube. com/watch?v=MLqyIICv8bA

Marx, K., \& Engels, F. (1978). Manifesto of the Communist Party. En R. C. Tucker (ed.). The Marx-Engels reader, $2^{a}$ ed. (pp. 469-500). Nueva York: W.W. Norton \& Company.

Massey, D. (2005). For space. Thousand Oaks: Sage Publications.

Masullo J. (2015). The power of staying put: Nonviolent resistance against armed groups in Colombia. Washington: International Center on Nonviolent Conflict.

Mitchell, C., \& Ramírez, S. (2009). Local peace communities in Colombia: An initial comparison of three cases. En V.M. Bouvier. Colombia: Building peace in a time of war (pp. 245-270). Washington: United States Institute of Peace. Moncada Hurtado, C., Cristancho Ossa, F., \& Caro Morales, A. M. (2011). Comunidad de Paz, resiste (Parte 1). Colombia: Universidad Católica de Pereira. Recuperado de https://www. youtube.com/watch? $v=j k V D m 4 w s r b$ 8\&list=PL3cBDgCi9tR3D1zuCfZ3z 2yG_fNQFNdfn\&index=1

Nieri, D. (ed.) (2007). Seminando vita e dignità. La Comunità di Pace di San José de Apartadó: 10 anni di resistenza nonviolenta alla guerra. Pisa: Quader- nia Satyagraha la forza della verità.

Oslender, U. (2016). The geographies of social movements: Afro-Colombian mobilization and the aquatic space. Durham: Duke University Press. 
Peluso, N. L., \& Lund, C. (2011). New frontiers of land control: Introduction. Journal of Peasant Studies, 38(4), 667-681.

Porto Gonçalves, C. W. (2006). A reinvenção dos territórios: A experiência latino americana e caribenha. En A. E. Ceceña (ed.) Los desafíos de las emancipaciones militarizado, (pp. 151-197). Buenos Aires: clasco.

Raffestin, C. (2012). Space, territory, and territoriality. Environment and Planning D: Society and Space, 30(1), 121-141.

Restrepo, E. (2002). Políticas de la alteridad: Etnización de "comunidad Negra" en el Pacífico sur colombiano. Journal of Latin American Anthropology, 7(2), 34-59.

Reyes, Á. (2015). Racialized spaces and pro- per places: Frantz Fanon, decolonization, and the rise of new territorialities. Ponencia presentada en el Institute of African American Research, Chapel Hill, usa.

Reyes, Á., \& Kaufman, M. (2011). Sovereignty, indigeneity, territory: Zapatista autonomy and the new practices of de- colonization. South Atlantic Quarterly, 110(2), 505-525.

Rojas, C. (2002). Civilization and violence: Regimes of representation in nineteenth- century Colombia. Minneapolis: University of Minnesota Press.

Rojas, C. (2007). Islands in the stream. A compartive analysis of zones of peace within Colombia's civil war. En L. E. Hancock, \& C. Mitchell (eds.). Zones of Peace (pp. 71-89). Bloomfield: Kumarian Press.

Sack, R. D. (1986). Human territoriality: Its theory and history. Cambridge: Cambridge University Press. 
Sánchez Ayala, L. (julio-septiembre 2015). De territorios, límites, bordes y fronte- ras: una conceptualización para abordar conflictos sociales. Revista de Estudios Sociales, 53, 175-179.

Santos, J. M. (23 de septiembre de 2015). Alocución del Presidente Juan Manuel Santos sobre el acuerdo en materia de justicia en el proceso de paz con las Farc. Presidencia de La República. La Habana. Recuperado de http://wp.presidencia. gov.co/Noticias/2015/ Septiembre/ Paginas/20150923_07-Alocucion-del-Presidente-JuanManuel-Santos-sobre- el-acuerdo-en-materia-de-justicia-en- elproceso-de-paz.aspx

Scott, J. (1990). Dominantion and the arts of resistance: Hidden transcripts. New Haven: Yale University Press.

Simon, R. I., Rosenberg, S., \& Eppert, C. (2000). Between hope and despair: The pedagogical encounter of historical re- membrance. En R. I. Simon, S. Rosen- berg, \& C. Eppert (eds.). Between hope and despair: Pedagogy and the remem- brance of historical trauma, (pp. 1-8). Landham: Rowman \& Littlefield Pu- blishers.

Ulloa, A. (2012). Los territorios indígenas en Colombia: de escenarios de apropiación transnacional a territorialidades alternatives. Scripta Nova: Revista electrónica de geografía y ciencias sociales, 16. Recuperado de http://www.ub.edu. libproxy.lib.unc.edu/geocrit/sn/sn418/sn-418-65.htm

Vachon, R. (2011). Kayanerekowa: A Mo- hawk perspective. En W. Dietrich, J. Echavarría Álvarez, G. Esteva, D. Ingruber, \& N. Koppensteiner. The Palgrave international handbook of peace studies: A cultural perspective, (pp. 330-351). Nueva York: Palgrave Macmillan.

Vasudevan, P. (2012). Performance and proximity: Revisiting environmental justice in Warren County, North Carolina. Performance Research, 17(4), 18-26. 
Wade, P. (2009). Defining blackness in Colombia. Journal de La Société Des Américanistes, 95(1), 165-184.

Wilderson, F. B. (2010). Red, white \& black: Cinema and the structure of US antagonisms. Durham: Duke University Press. Zamosc, L. (1986). The agrarian question and the peasant movement in Colombia: Struggles of the National Peasant Association 1967-1981. Cambridge: Cambridge University Press.

Zamosc, L. (1986). The agrarian question and the peasant movement in Colombia: Struggles of the National Peasant Association 19671981. Cambridge: Cambridge University Press. 

Territorios de paz: otras territorialidades en la Comunidad de Paz de San José de Apartadó, Colombia 

Territorios de paz: otras territorialidades en la Comunidad de Paz de San José de Apartadó, Colombia 